\title{
The key to simplified management of an undescended parathyroid adenoma
}

\section{La clave para el manejo simplificado de un adenoma paratiroideo no descendido}

\author{
Humberto Ruiz-Hernández ${ }^{1,2 *}$, Joyce Meza-Venegas ${ }^{2,3}$, and Samuel K. Snyder ${ }^{4,5}$

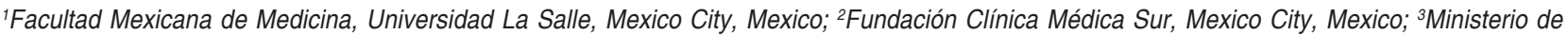 \\ Salud Pública de Ecuador, Quito, Ecuador; ${ }^{4}$ University of Texas Rio Grande Valley School of Medicine, Texas, USA; ${ }^{5}$ Doctor's Hospital at \\ Renaissance, Edinburg, Texas
}

\begin{abstract}
Undescended parathyroid adenoma is a rare cause of primary hyperparathyroidism that happens $<1 \%$ of cases. If not suspected, it can lead to a negative bilateral parathyroid exploration and extensive iatrogenic trauma. We propose that with proper imaging the correct diagnosis can be established to simplify surgical management. We describe two cases of patients who underwent a targeted neck exploration due to an undescended parathyroid adenoma diagnosed with an appropriate preoperative imaging protocol. With an appropriate imaging protocol for primary hyperparathyroidism and parathyroid hormone aspirates, an undescended parathyroid adenoma can be primarily diagnosed to guide a focused parathyroidectomy.
\end{abstract}

Key words: Endocrine surgery. Endocrine tumor. Ectopic parathyroid adenoma. Endocrine surgical procedures. Endocrine gland neoplasms. Parathyroid neoplasms.

\section{Resumen}

El adenoma paratiroideo no descendido ocasiona hiperparatiroidismo primario en $<1 \%$ de los casos. Si no se sospecha, puede llevar a exploraciones negativas y trauma iatrogénico extenso. Proponemos que, con un protocolo imagenológico adecuado, se puede realizar un diagnóstico correcto, simplificando el abordaje quirúrgico. Describimos dos casos en que se realizó una exploración de cuello dirigida debido a un adenoma paratiroideo no descendido diagnosticado con un protocolo de imagen preoperatorio apropiado. Un protocolo de imagen apropiado para hiperparatiroidismo primario y aspirados de PTH pueden diagnosticar de manera inicial un adenoma paratiroideo no descendido para guiar una paratiroidectomía dirigida.

Palabras clave: Cirugía endócrina. Tumor endócrino. Adenoma paratiroideo ectópico. Procedimientos quirúrgicos endocrinos. Neoplasias de glándulas endocrinas. Neoplasias paratiroideas.

\section{Introduction}

Undescended parathyroid adenomas are defined as glands located $1 \mathrm{~cm}$ or more cranial to the superior pole of the thyroid gland, and represent only $2-7 \%$ of the ectopic parathyroid adenomas. An ectopic location occurs in $16 \%$ of parathyroid adenomas. This makes undescended parathyroid adenomas a rare cause of

\footnotetext{
Correspondence:

*Humberto Ruiz-Hernández

Paseo Toltecas \#292 Aquiles Serdán,

Date of reception: 29-09-2020

C.P.: 42034, Pachuca de Soto, Hgo., Mexico Date of acceptance: 27-11-2020

E-mail: humbertoruizhernandez@gmail.com

DOI: $10.24875 / C I R U .20001056$

Cir Cir. 2021;89(S1):37-42

Contents available at PubMed

www.cirugiaycirujanos.com

0009-7411/@ 2020 Academia Mexicana de Cirugía. Published by Permanyer. This is an open access article under the terms of the CC BY-NC-ND license (http://creativecommons.org/licenses/by-nc-nd/4.0/).
} 
primary hyperparathyroidism, accounting for just $0.91 \%$ of the cases or less ${ }^{1}$.

This anomaly is due to an undetermined error in the fetal development and normal descent of the parathyroid glands to their typical adult location. In the $5^{\text {th }}$ week of the embryogenesis the parathyroid glands arise from endodermal epithelial cells ${ }^{2}$. The inferior parathyroid glands originate from the dorsal epithelium of the $3^{\text {rd }}$ pharyngeal pouch with the thymus gland originating from the ventral aspect. The parathyroid migrates inferiorly and separates from the thymus to rest near the lower pole of the thyroid. The superior parathyroid glands originate from the dorsal epithelium of the $4^{\text {th }}$ pharyngeal pouch and descend with the ultimobranchial body to reside close to the mid superior lobe. The superior parathyroid gland can fail to descend or end up in a more posterior location near the thyroid with less cranial-caudal displacement than the inferior parathyroid gland ${ }^{3}$.

Technetium sestamibi scintigraphy and ultrasound are the most common modalities used to localize adenomas and are often complementary. Historically, computed tomography (CT) imaging has generally been reserved for those patients in whom initial surgery has failed or those who have recurrent hyperparathyroidism despite treatment ${ }^{4}$. More recently, a 4D CT scan uses timed imaging after intravenous contrast to identify a hypervascular parathyroid adenoma. This imaging modality is helpful for adenoma localization when the initial studies are negative or for confirmation of a suspected ectopic parathyroid adenoma ${ }^{5}$.

\section{Case 1}

We present the case of a 57-year-old male who was discovered to have an elevated calcium for at least 1 year, complaining of tiredness and difficulty with his memory and concentration. There was a negative history of kidney stones or bone-related abnormalities. Clinical examination identified prominent submandibular salivary glands bilaterally (left $>$ right), without any regional adenopathy, thyromegaly, venous distention, carotid bruit, tenderness, or any palpable thyroid nodules. Vital signs were blood pressure $141 / 86 \mathrm{mmHg}$, with a ventricular rate of $77 \mathrm{bpm}$. The previous testing revealed a 24-h urine calcium at $402 \mathrm{mg}$ (normal values: $100-300 \mathrm{mg}$ ), serum calcium of $11.2 \mathrm{mg} / \mathrm{dl}$ (normal values: 8-10 $\mathrm{mg} / \mathrm{dl})$, parathyroid hormone $(\mathrm{PTH})$ level of $208 \mathrm{ng} / \mathrm{ml}$ (normal values under $67 \mathrm{ng} / \mathrm{ml}$ ), and low $25 \mathrm{OH}$ Vitamin-D at 14 (normal 30-80). The patient

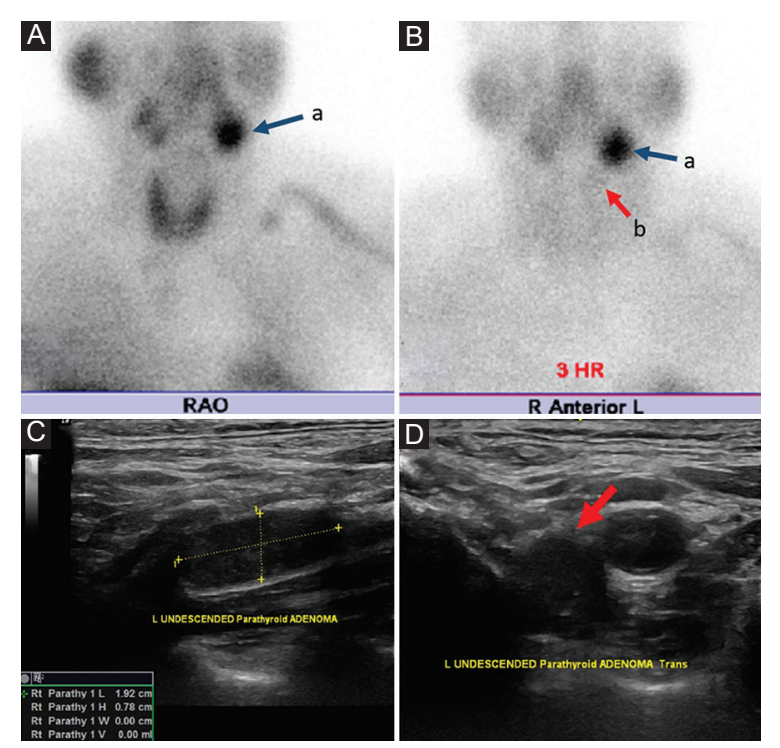

Figure 1. Initial Image Studies; A.- Parathyroid Sestamibi Scan performed at $15 \mathrm{~min}$ after the Tecnessium Sestamibi injection B. $3 \mathrm{~h}$ after injection. A: left Submandibular gland. B: apparent separate focus of ratio activity. C: longitudinal Neck Ultrasound depicting a hypoechoic nodule medial to the bifurcation of the left carotid artery. D: axial cut.

had a parathyroid sestamibi scan at an outside institution. Images were taken at $15 \mathrm{~min}$ and $3 \mathrm{~h}$ after the injection of technetium sestamibi (Fig. 1). Images were reviewed by the surgeons. This demonstrated marked uptake in the left submandibular gland area compared to the right submandibular salivary gland. Delayed films appeared to indicate a separate focus of radioactivity to the initial uptake and persistent intense uptake in the left submandibular salivary gland area. These images suggested the possibility of an undescended parathyroid adenoma in the left neck but were not clearly diagnostic. A surgeon-performed cervical ultrasound examination revealed a normal sized thyroid and without imaging any abnormal parathyroid glands in the central neck near the thyroid gland or in the lower paratracheal area (Fig. 1). The lateral and upper neck were imaged with ultrasound looking for the possibility of an undescended parathyroid adenoma and initially, a small nodule was discovered medial to the bifurcation of the left common carotid artery that was felt to represent the rare presence of a lymph node medial to the carotid artery bifurcation or an undescended parathyroid adenoma. The patient underwent a 4D CT scan with spiral CT imaging without contrast and then arterial phase and venous phase imaging after the injection of intravenous contrast (Fig. 2). This revealed a $9.3 \mathrm{~mm} \times 19.2 \mathrm{~mm}$ enhancing nodule medial and posterior to the distal left common carotid just 

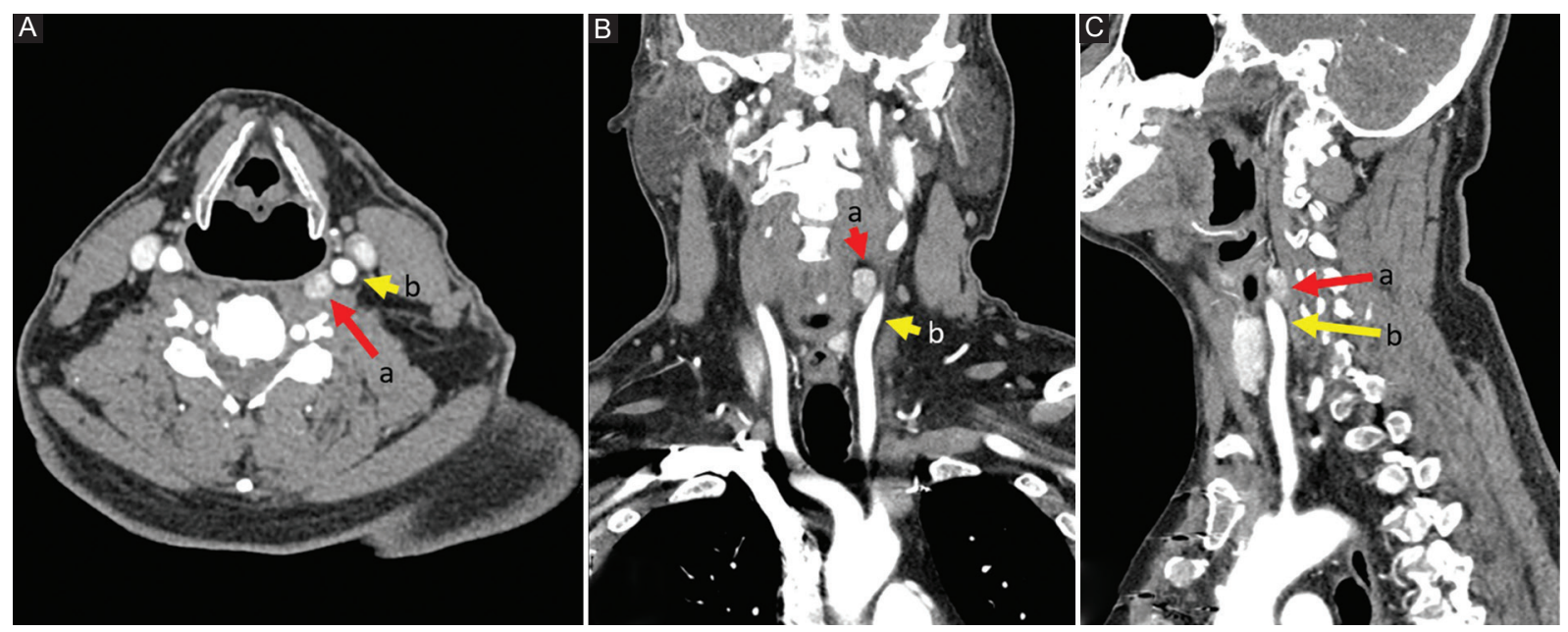

Figure 2. Parathyroid 4D CT Scan. A: axial cut at C4 level arterial phase. B: coronal Reconstruction arterial phase. C: lateral reconstruction arterial phase. (a) Enhancing nodule. (b) Left common carotid artery.

inferior to the carotid artery bifurcation. A large left submandibular salivary gland was confirmed. Directed reexamination of the left lateral and upper neck with surgeon-performed ultrasound identified a deep hypoechoic nodule of $1.92 \times 0.78 \times 1.01 \mathrm{~cm}$ located medial and posterior to the bifurcation of the left carotid artery. Laterally, this was close to the level of the thyroid cartilage notch. On the basis of this evidence the patient underwent a targeted left neck exploration and excision of the abnormal parathyroid gland using gamma probe localization of the adenoma after the injection of technetium sestamibi $1 \mathrm{~h}$ before the operation, intraoperative PTH monitoring, and intraoperative nerve monitoring (Fig. 3). The gamma probe skin counts were 4600 counts/s. A $2.5 \mathrm{~cm}$ transverse incision in the direction of a natural skin crease was made over the lateral border of the sternohyoid muscle and medial border of the sternocleidomastoid muscle. The dissection was carried down between the sternohyoid and sternocleidomastoid muscles, medial to the identified carotid artery, down to the deeper cervical tissues. A small nodule was palpable there consistent with a possible parathyroid adenoma. The in vivo gamma probe counts over this nodule were 5500 counts/s indicating the likelihood of this nodule being a parathyroid adenoma. The nodule was carefully mobilized up into the wound, ligating feeding blood vessels before excising. The ex vivo gamma counts of the nodule were 2000 counts/s (36\% of in vivo gamma counts), confirming the nodule as consistent with a parathyroid adenoma. The intraoperative PTH levels dropped from 245 preincision to 121 preexcision and then 40.9 and

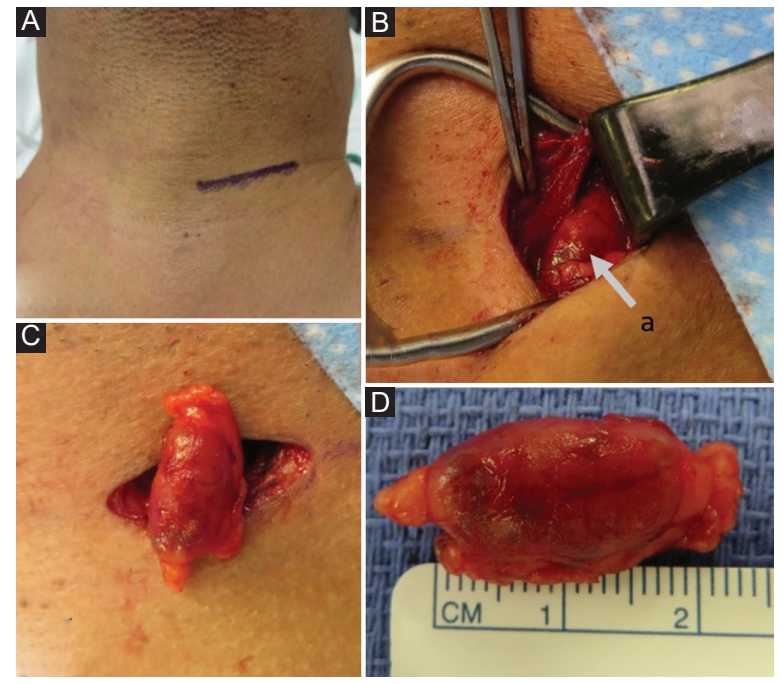

Figure 3. Intraoperative images. A: place and size of incision, B: in vivo localization of the adenoma (a) lateral to the sternohyoin muscle pointed by the pick up. C: ex vivo Depiction of the adenoma over surgical incision. D: measurement of the resected adenoma.

32.8, respectively, 5 and 10 min after the excision of the undescended parathyroid gland. The gland weighed $1130 \mathrm{mg}$ and was confirmed by pathology as a parathyroid adenoma.

\section{Case 2}

An 80-year-old male with a history of Parkinsonism presented for evaluation of hypercalcemia secondary 
to primary hyperparathyroidism. Recent calcium level was elevated most at 10.7, with a prior level of 11.7 and a PTH of 74 at the same time. Vitamin D level was 59 . He was experiencing fatigue, weakness as well as problems with concentration and memory which he also attributed to his Parkinson's. A surgeon-performed cervical ultrasound examination revealed a normal sized thyroid without imaging any abnormal parathyroid glands in the central neck near the thyroid gland or in the lower paratracheal area (Fig. 4). The lateral and upper neck were imaged with ultrasound looking for the possibility of an undescended parathyroid adenoma and initially, found a single nodule medial to the bifurcation of the common carotid artery that was felt to represent the rare presence of a lymph node medial to the carotid artery bifurcation or an undescended parathyroid adenoma. Fine-needle aspirate (FNA) with PTH of the nodule was done. He underwent a 4D CT scan with spiral CT imaging without contrast and then arterial phase and venous phase imaging after the injection of intravenous contrast (Fig. 4). This revealed an oval nodule measuring $7 \times 5 \mathrm{~mm}$ anterior to the left common carotid artery just below the bifurcation. The lesion was isodense to musculature on precontrast sequence with marked arterial enhancement and partial washout on venous phase. Ultrasound-guided FNA reported cellular aspirate with bland overlapping cells and no colloid. Immunostain for PTH was reported negative, but in light of the clinical suspicion of parathyroid gland, and despite the equivocal PTH stain, morphologic features were highly suggestive of parathyroid tissue. Therefore, a $2 \mathrm{ml}$ saline washout from FNA of suspected ectopic parathyroid was performed reporting PTH, FNA: $9724 \mathrm{pg} / \mathrm{ml}$. On the basis of this evidence the patient underwent a targeted left neck exploration and excision of the abnormal parathyroid gland using intraoperative PTH monitoring and intraoperative nerve monitoring (Fig. 5). A $2.5 \mathrm{~cm}$ transverse incision in the direction of a natural skin crease was made over the lateral border of the sternohyoid muscle and medial border of the sternocleidomastoid muscle. The dissection was carried down between the sternohyoid and sternocleidomastoid muscles, anterior to the identified carotid artery. A small nodule was palpable there consistent with a possible parathyroid adenoma. The nodule was carefully mobilized up into the wound, ligating feeding blood vessels before excising. The intraoperative PTH levels dropped from 58 preincision to 23 preexcision and then 9 and 8 , respectively,

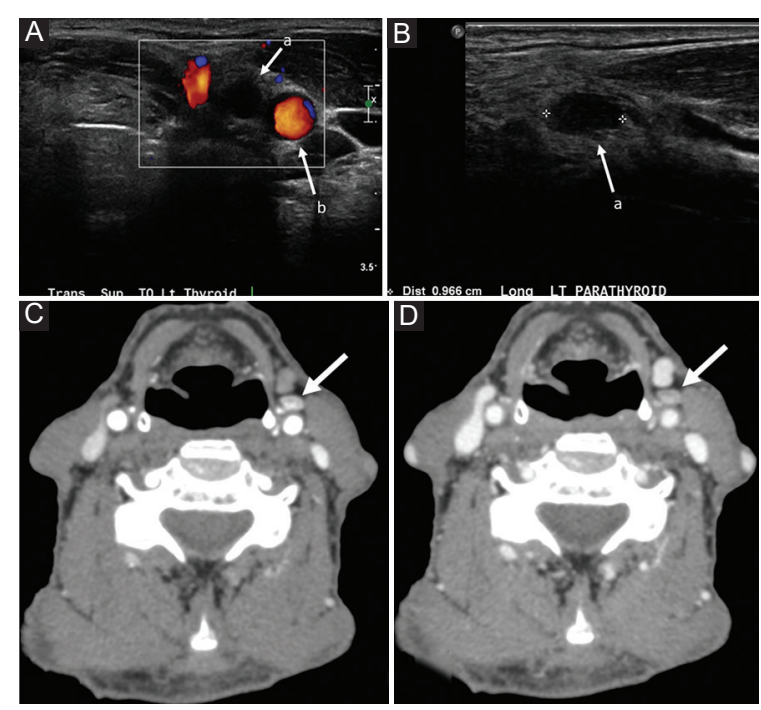

Figure 4. Image Studies; A: axial Neck Ultrasound depicting a hypoechoic nodule (a) medial to the bifurcation of the left carotid artery (b). B: Longitudinal cut. C: parathyroid 4D CT Scan on Arterial Phase. D: venous Phase depicting enhancing nodule.

5 and 10 min after the excision of the undescended parathyroid gland. The gland weighed $0635 \mathrm{mg}$ and was confirmed by pathology as a parathyroid adenoma.

\section{Discussion}

Persistent hyperparathyroidism after failed cervical exploration usually occurs in $<10 \%$ of these procedures $^{6}$ and is due to an ectopic parathyroid adenoma in $7 \%$ of cases $^{7}$. For these patients, the identification of an occult lesion is key in decreasing morbidity associated with surgical exploration ${ }^{8}$. It has been stated that the major cause of operative failure is the surgeon's inability to find the abnormal parathyroid glands $(76.2 \%)^{9}$ and most cases of persistent or recurrent HPT after parathyroidectomy are due to missed glands in normal or ectopic locations ${ }^{10}$. For cases whereby sonography and sestamibi do not reproduce localizable lesions, evaluation with a cross-sectional imaging technique may be necessary. Studies have shown increased rates of recurrent laryngeal nerve injury and permanent hypocalcemia in patients who underwent reoperation for persistent primary hyperparathyroidism ${ }^{11}$.

What imaging protocol would work best for identifying an undescended parathyroid adenoma before a central neck parathyroid exploration? Ultrasound by an experienced endocrine radiologist or endocrine surgeon should be attempted first. A parathyroid adenoma 

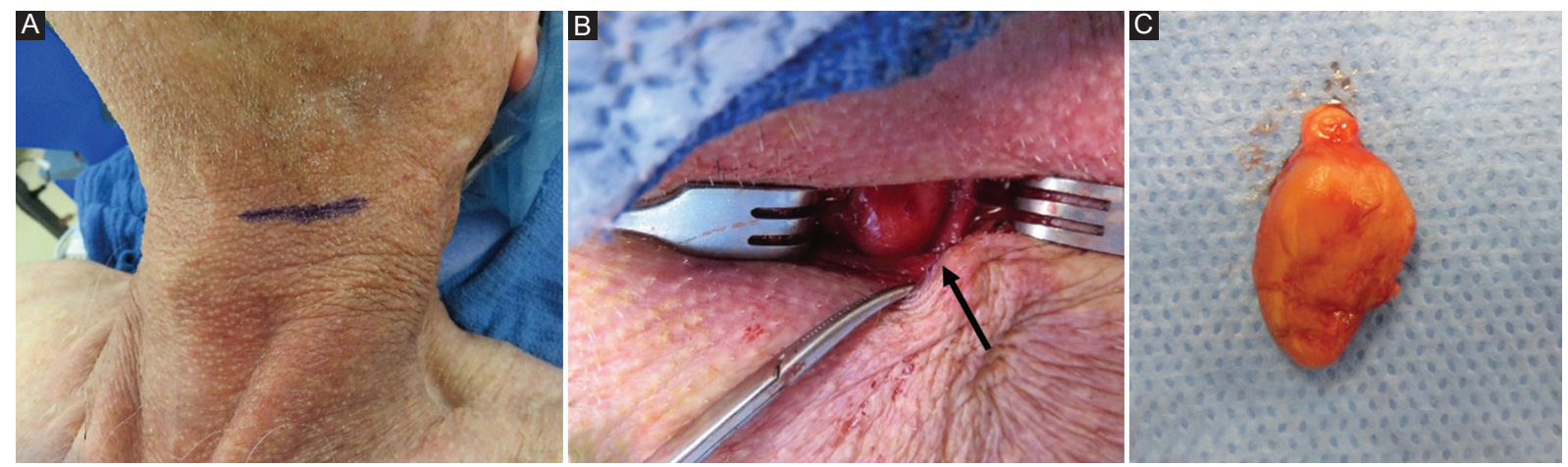

Figure 5. Intraoperative images. A: place and size of incision. B: in vivo localization of the adenoma. C: ex vivo Depiction of the adenoma $0.8 \mathrm{~cm}$.

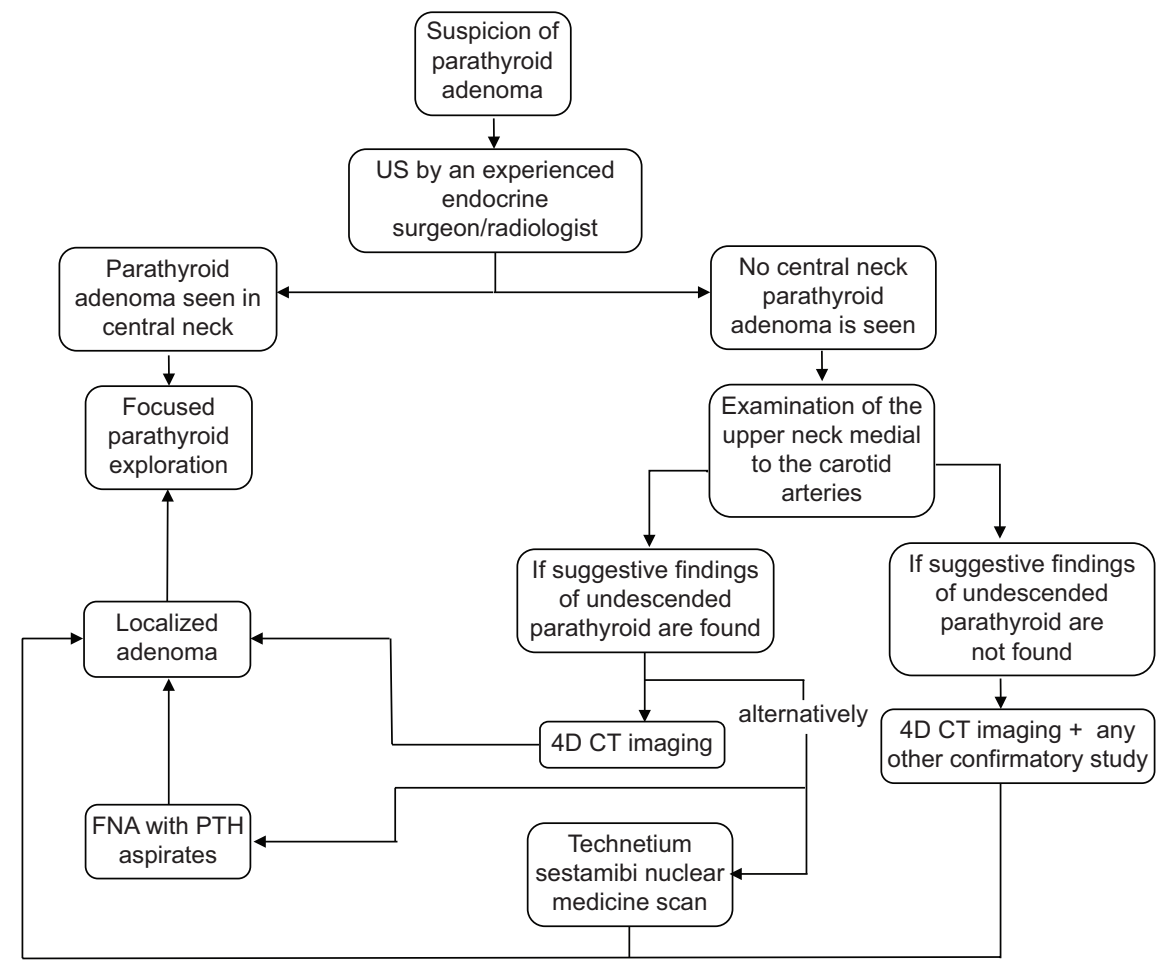

Figure 6. Proposed image protocol algorithm for localizing parathyroid undescended adenoma.

clearly seen in the central neck supports proceeding with a focused parathyroid exploration. Examination of the upper neck medial to the carotid arteries should be done if no central neck parathyroid adenoma is identified. Undescended parathyroid adenomas are typically located medial to the bifurcation of the carotid artery. Lymph nodes in the upper neck are typically lateral to the carotid artery and medial or lateral to the internal jugular vein. Therefore, under these circumstances, finding a hypoechoic nodule medial to the bifurcation of the carotid artery without clear imaging evidence of a lymph node with a hyperechoic fatty hilum should raise suspicion for an undescended parathyroid adenoma. The approach to ectopic parathyroid adenomas generally requires confirmation with a second imaging study, either a technetium sestamibi nuclear medicine scan or 4D CT scan. However, it has been reported that initial nuclear medicine parathyroid sestamibi scan can read as within normal limits ${ }^{12}$ and even though the use of sestamibi SPECT/CT can reduce false negative interpretations on technetium 99 m sestamibi scintigraphy ${ }^{13}$, we would favor the $4 \mathrm{D} C \mathrm{CT}$ imaging majorly due to its 
anatomic clarity compared with technetium $99 \mathrm{~m}$ sestamibi scintigraphy and its higher diagnostic performance when compared with sestamibi SPECT/CT. Alternately, an undescended parathyroid adenoma that can be seen on ultrasound lends itself to further evaluation with FNA that includes PTH aspirates ${ }^{14}$. An elevated PTH aspirate confirms the presence of parathyroid tissue. The key to discovering an undescended parathyroid adenoma is the initial suspicion when the central neck ultrasound is negative for a parathyroid adenoma, leading to scanning the upper neck medial to the carotid arteries, followed best with a 4D CT scan for anatomic localization of the relatively hyper vascular parathyroid adenoma.

\section{Conclusion}

Undescended parathyroid adenomas are rare and are likely to be missed on standard parathyroid workup. It is an ectopic site that merits attention on any patient not only after a failed central neck exploration but should be considered when ultrasound imaging of the central neck is negative for a parathyroid adenoma. The appropriate imaging protocol uses ultrasound imaging medial to the carotid artery that can potentially identify the undescended parathyroid adenoma near the bifurcation of the carotid artery (Fig. 6). The localization can then be confirmed with a 4D-CT scan, nuclear medicine technetium sestamibi scan, or ultrasound-guided PTH aspiration. Localization directs primary minimally invasive parathyroidectomy surgery in the upper neck through a small incision.

\section{Acknowledgments}

The authors would like to thank Doctor's Hospital at Renaissance.

\section{Conflicts of interest}

The authors declare that there is no conflicts of interest.

\section{Ethical disclosures}

Protection of human and animal subjects. The authors declare that no experiments were performed on humans or animals for this study.

Confidentiality of data. The authors declare that they have followed the protocols of their work center on the publication of patient data.

Right to privacy and informed consent. The authors have obtained the written informed consent of the patients or subjects mentioned in the article. The corresponding author is in possession of this document.

\section{References}

1. Lee J, Mazeh H, Serpell J, Delbridge L, Chen H, Sidhu S. Adenomas of cervical maldescended parathyroid glands: pearls and pitfalls. ANZ $J$ Surg. 2012;85:957-61.

2. Rioja P, Mateu G, Lorente-Poch L, Sancho J, Sitges-Serra A. Undescended parathyroid adenomas as cause of persistent hyperparathyroidism. Gland Surg. 2015;4:295-300.

3. Snyder SK. In: Stack BC, Bodenner DL, editors. Surgery for Ectopic Parathyroid; or: medical and Surgical Treatment of Parathyroid Diseases: an Evidence-based Approach. $1^{\text {st }}$ ed. Little Rock, AR, USA: Springer International Publishing; 2017. p. 281-303.

4. Devcic Z, Jeffrey R, Kamaya A, Desser T. The elusive parathyroid adenoma. Ultrasound Quart. 2013;29:179-87.

5. Chazen JL, Gupta A, Dunning A, Phillips CD. Diagnostic accuracy of 4D-CT for parathyroid adenomas and hyperplasia. Am J Neuroradiol. 2012;33:429-33.

6. Wong KK, Fig LM, Gross MD, Dwamena BA. Parathyroid adenoma localization with 99mTc-sestamibi SPECT/CT: a meta-analysis. Nucl Med Commun. 2015;36:363-75.

7. Kim J, Cubangbang M, Adkins L, Chia S, DeKlotz T, Boyle L, et al. Ectopic parathyroid adenoma in the pyriform sinus. Head Neck. 2017;39:E110-3.

8. Dhillon V, Pitukcheewanont P, Yeh M, Maceri D. Identifying an ectopic parathyroid adenoma using 4DCT in a pediatric patient with persistent primary hyperparathyroidism. Case Rep Otolaryngol. 2013;2013:1-4.

9. Lew J. Operative failure in the era of focused parathyroidectomy. Arch Surg. 2010;145:628.

10. Silberfein E. Reoperative parathyroidectomy. Arch Surg. 2010;145:1065.

11. Beland M, Mayo-Smith W, Grand D, Machan J, Monchik J. Dynamic MDCT for localization of occult parathyroid adenomas in 26 patients with primary hyperparathyroidism. Am J Roentgenol. 2011;196:61-5.

12. Kordahi A, Newfield R, Bickler S, Mo J, Khanna P, Bykowski J, et al. Undescended retropharyngeal parathyroid adenoma with adjacent thymic tissue in a 13-year-old boy with primary hyperparathyroidism. Oxford Med Case Reports. 2019;2019:519-23.

13. Mahajan S, Schoder H. Ectopic undescended parathyroid adenoma-SPECT/CT avoids false-negative interpretation on 99mTc-MIBI dual-phase scintigraphy. Clin Nucl Med. 2018;43:199-200.

14. Maser C, Donovan P, Santos F, Donabedian R, Rinder C, Scoutt L, et al. Sonographically guided fine needle aspiration with rapid parathyroid hormone assay. Ann Surg Oncol. 2006;13:1690-5. 